\title{
Permeation of atmospheric gases through polymer O-rings used in flasks for air sampling
}

\author{
P. Sturm, ${ }^{1}$ M. Leuenberger, ${ }^{1}$ C. Sirignano, ${ }^{2}$ R. E. M. Neubert, ${ }^{2}$ H. A. J. Meijer, ${ }^{2}$ \\ R. Langenfelds, ${ }^{3,4}$ W. A. Brand, ${ }^{5}$ and Y. Tohjima ${ }^{6}$ \\ Received 14 August 2003; revised 17 December 2003; accepted 22 December 2003; published 25 February 2004.
}

[1] Permeation of various gases through elastomeric O-ring seals can have important effects on the integrity of atmospheric air samples collected in flasks and measured some time later. Depending on the materials and geometry of flasks and valves and on partial pressure differences between sample and surrounding air, the concentrations of different components of air can be significantly altered during storage. The influence of permeation is discussed for $\mathrm{O}_{2} / \mathrm{N}_{2}, \mathrm{Ar} / \mathrm{N}_{2}, \mathrm{CO}_{2}, \delta^{13} \mathrm{C}$ in $\mathrm{CO}_{2}$, and water vapor. Results of sample storage tests for various flask and valve types and different storage conditions are presented and are compared with theoretical calculations. Effects of permeation can be reduced by maintaining short storage times and small partial pressure differences and by using a new valve design that buffers exchange of gases with surrounding air or by using less permeable materials (such as Kel-F) as sealing material. General awareness of possible permeation effects helps to achieve more reliable measurements of atmospheric composition with flask sampling techniques. INDEX TERMS: 0394 Atmospheric Composition and Structure: Instruments and techniques; 1694 Global Change: Instruments and techniques; 1610 Global Change: Atmosphere (0315, 0325); 1615 Global Change: Biogeochemical processes (4805); KEYWORDS: permeation, air sampling, storage effects

Citation: Sturm, P., M. Leuenberger, C. Sirignano, R. E. M. Neubert, H. A. J. Meijer, R. Langenfelds, W. A. Brand, and Y. Tojhima (2004), Permeation of atmospheric gases through polymer O-rings used in flasks for air sampling, J. Geophys. Res., 109, D04309, doi:10.1029/2003JD004073.

\section{Introduction}

[2] Flask sampling of atmospheric air is an important tool in climate research to investigate atmospheric composition changes on regional to global spatial scales and on timescales from hours to decades. Especially for remote sites and for airborne campaigns, often the only way to obtain measurements is to collect air in glass flasks in situ and to analyze the samples later in a laboratory equipped with measuring instruments. This increases the risk of altering the composition of the air either during the sampling procedure or during the storage prior to measurement. To minimize such adverse effects, one must choose appropriate filling procedures and flask materials.

[3] In the case of atmospheric $\mathrm{O}_{2}$ concentrations these gas handling aspects prove to be particularly crucial [Keeling et

\footnotetext{
${ }^{1}$ Climate and Environmental Physics, Physics Institute, University of Bern, Bern, Switzerland.

${ }^{2}$ Centrum voor IsotopenOnderzoek, University of Groningen, Groningen, Netherlands.

${ }^{3}$ Commonwealth Scientific and Industrial Research Organisation Atmospheric Research, Aspendale, Australia.

${ }^{4}$ Institute of Antarctic and Southern Ocean Studies, University of Tasmania, Hobart, Tasmania, Australia.

${ }^{5}$ Max Planck Institute for Biogeochemistry, Jena, Germany.

${ }^{6}$ Atmospheric Environment Division, National Institute for Environmental Studies, Tsukuba, Japan.
}

Copyright 2004 by the American Geophysical Union. 0148-0227/04/2003JD004073\$09.00 al., 1998]. Measurements of the $\mathrm{O}_{2}$ concentration can provide important constraints on the global carbon cycle [Keeling et al., 1993]; however, they are challenging because the variations occur only at the parts per million (ppm) level relative to the large $21 \% \mathrm{O}_{2}$ content. Any small disturbance of sample air can thus result in a similar or bigger signal compared with the real atmospheric variations.

[4] To reduce adsorption and desorption of gas molecules on surfaces, the flasks most commonly used for $\mathrm{O}_{2}$ measurements are made of glass. There exist different valve designs; however, all flasks currently in use for this task are sealed by a polymer material, which is pressed against the glass surface of the valve. All polymers are subject to permeation of gases, which therefore limits the effectiveness of the seal if partial pressure differences between sample and surrounding air exist.

[5] Processes other than permeation may also influence the stability of the sample composition. For instance, selective outgassing or physical adsorption of gases on O-rings as well as oxidation of grease used to lubricate the O-rings can cause changes of the air composition. Keeling et al. [1998] reported a depletion in the $\mathrm{O}_{2} / \mathrm{N}_{2}$ ratio and $\mathrm{CO}_{2}$ concentration in $5 \mathrm{~L}$ glass flasks fitted with Viton O-rings and filled to $1000 \mathrm{hPa}$ pressure with 20 extra O-rings inserted in the flasks. Flasks with no extra O-rings, however, showed no significant drifts over 313 days in accordance with the findings of Bender et al. [1996].

[6] In this paper we report on the permeation process of different gases and various O-ring materials used for glass 
valves. Because of the sensitivity of high-precision $\mathrm{O}_{2} / \mathrm{N}_{2}$ measurements to small interferences we focus particularly on $\mathrm{O}_{2} / \mathrm{N}_{2}$. Additionally, water vapor, $\mathrm{Ar} / \mathrm{N}_{2}, \mathrm{CO}_{2}$, and $\delta^{13} \mathrm{C}$ in $\mathrm{CO}_{2}$ are discussed. Section 2 summarizes theoretical considerations on the permeation process and shows the time dependence of the permeation rate for helium through a Viton O-ring. Section 3 deals with changes of sample air composition with increasing storage time and compares measured to calculated permeation rates. Tests with various O-ring materials and different storage conditions are presented. In section 4 storage drift measurements and permeation calculations of flasks sealed with new double O-ring valves are discussed. Finally, section 5 summarizes our major findings.

\section{Permeation Process}

\subsection{Theory}

[7] Permeation is commonly viewed as a three-step process. First, gas dissolves into the solid's surface; then it diffuses through the solid; and finally, it desorbs from it. The time dependence of the permeation rate is determined by the diffusion process because the solution and desorption occur on much shorter timescales than the diffusion through the solid [Perkins, 1973]. The concentration $c$ of the diffusing species in the solid's surface is given by Henry's law,

$$
c=S p
$$

where $S$ is the solubility coefficient and $p$ is the gas pressure. Diffusion of the dissolved gas into the interior is governed by Fick's second law,

$$
\frac{\partial c}{\partial t}=D \nabla^{2} c
$$

where $D$ is the concentration-independent, isotropic diffusion coefficient. If we consider a planar membrane with a large area-to-thickness ratio, equation (2) can be reduced to a one-dimensional form

$$
\frac{\partial c}{\partial t}=D\left(\frac{\partial^{2} c}{\partial x^{2}}\right)
$$

where $x$ is the coordinate perpendicular to the membrane. Assuming that the membrane is initially free of gas and that the concentrations of gas at the two surfaces are fixed at $c_{1}$ and $c_{2}$, respectively, the initial and boundary conditions are

$$
\begin{aligned}
& c(x, t=0)=0 \\
& c(x=0, t)=c_{1} \\
& c(x=d, t)=c_{2},
\end{aligned}
$$

where $d$ denotes the membrane thickness. The solution of equation (3) consistent with equations (4a), (4b), and (4c) is [Barrer, 1941]

$$
\begin{aligned}
c(x, t)= & c_{1}+\left(c_{2}-c_{1}\right) \frac{x}{d} \\
& +\frac{2}{\pi} \sum_{n=1}^{\infty} \frac{c_{2} \cos n \pi-c_{1}}{n} \sin \frac{n \pi x}{d} \exp \left(-\frac{D n^{2} \pi^{2} t}{d^{2}}\right) .
\end{aligned}
$$

The flux of diffusing species is given by Fick's first law,

$$
J=-D \nabla c .
$$

The gas flux through the low-pressure surface of the wall can then be calculated from equations (5) and (6):

$$
\begin{aligned}
J(x=d, t)= & \frac{D\left(c_{1}-c_{2}\right)}{d} \\
& +\frac{2 D}{d} \sum_{n=1}^{\infty}\left[(-1)^{n} c_{1}-c_{2}\right] \exp \left(-\frac{D n^{2} \pi^{2} t}{d^{2}}\right) .
\end{aligned}
$$

For large values of $t$ one obtains the steady state flux

$$
J(x=d, t \rightarrow \infty)=\frac{D\left(c_{1}-c_{2}\right)}{d}=\frac{D S\left(p_{1}-p_{2}\right)}{d} .
$$

The product

$$
K=D S
$$

is the permeation coefficient. It has, like the diffusion and solubility coefficient, a strong (approximately exponentiallike) dependence on temperature. Finally, the steady state permeation flux $F$ of a gas exposed with a partial pressure difference $\left(p_{1}-p_{2}\right)$ to a membrane of thickness $d$ and surface area $A$ is

$$
F=A J(x=d, t \rightarrow \infty)=K \frac{A\left(p_{1}-p_{2}\right)}{d} .
$$

\subsection{Measurement of Time-Dependent Permeation Rate}

[8] Flasks used at the Physics Institute, University of Bern, are each equipped with two high-vacuum valves (Louwers Hapert, Netherlands). The valves are opened and closed by moving a cylindrical plug in and out of a $9 \mathrm{~mm}$ ID valve tube (see Figure 1a). An O-ring sitting in a notch on the plug seals the flask volume from surrounding air. The O-ring material is Viton (FKM 70-Copolymercompound 51414-GenuineViton $\left.{ }^{\circledR} \mathrm{A}\right)$.

[9] Although the property of a large area-to-thickness ratio is not true for an O-ring, the one-dimensional consideration of the permeation process is still justified for this valve type because the sealing O-ring is mounted on and enclosed by impermeable cylindrical glass, which acts as a boundary in two dimensions. According to the size of the valves and O-rings the effective thickness and exposed surface area of an O-ring can be estimated. For our flasks the O-ring thickness and surface area are $\sim 1.7 \mathrm{~mm}$ and $\sim 20 \mathrm{~mm}^{2}$, respectively, per valve. Unless otherwise specified, all calculations presented in this paper are based on these O-ring dimensions.

[10] To make sure that the changes in sample composition we observe in these flasks are primarily due to permeation and are not a result of leaks, we conducted an experiment using these flasks and a helium leak detector. The previously evacuated flasks had been filled to $950 \mathrm{hPa}$ with helium, and the flux through the Viton O-ring valve was subsequently measured by the leak detector. The temperature was $\sim 20^{\circ} \mathrm{C}$. Figure 2 shows the permeation flux as a function of time. Instead of a sharp signal increase as expected from a real leak, the leak detector's helium signal slowly increased 


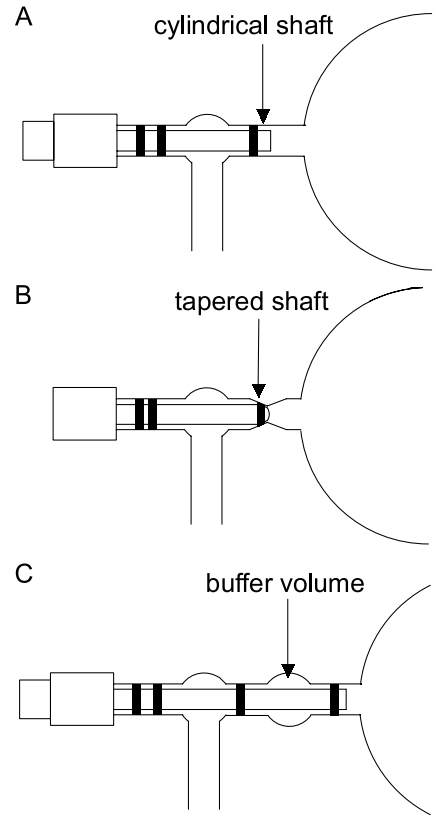

Figure 1. Schematic diagram of different flask valves: (a) valve with cylindrical shaft (Louwers Hapert, Netherlands), (b) valve with tapered shaft (Glass Expansion, Melbourne, Australia), and (c) double O-ring valve with buffer volume.

because of permeation. Steady state permeation was achieved in $\sim 40 \mathrm{~min}$. The solid line in Figure 2 is a least squares fit of equation (7) to the measured data. The fitted parameters are the permeation and solubility coefficients $K$ and $S$, respectively. We obtain a solubility coefficient of $S_{\mathrm{He}}=2.3 \times 10^{-5} \mathrm{hPa}^{-1}$ and a permeation coefficient of $K_{\mathrm{He}}=15.1 \times 10^{-15} \mathrm{~m}^{2} \mathrm{~s}^{-1} \mathrm{hPa}^{-1}$, which is in agreement with the values listed in Table 1 .

[11] Given the O-ring geometry and permeation coefficients for different gases, we can estimate the influence of permeation on sample air composition for different sample pressures and flask volumes. However, the uncertainty in the O-ring dimensions and the large range of some permeation coefficients shown in Table 1 restrict the precision of such an estimate. The scatter of results in Table 1 is probably mainly due to modifications in polymer manufacturing over the last decades and the fact that the polymers may vary between different manufacturers. The composition of a polymer can cause properties to differ by orders of magnitude. It is therefore essential to compare theoretical calculations with measured drifts in sample air composition as a function of storage time.

\section{Flask Storage Drift}

\subsection{Permeation Influence on $\mathrm{O}_{2} / \mathbf{N}_{2}$}

[12] We express changes in elemental and isotopic ratios as relative deviations from a reference gas. In the case of $\mathrm{O}_{2} / \mathrm{N}_{2}$, variations are reported in units of per meg (where 1 per meg $=0.001 \%$ ) according to $\delta \mathrm{O}_{2} / \mathrm{N}_{2}=\left[\left(\mathrm{O}_{2} / \mathrm{N}_{2}\right)_{\text {sample }} /\right.$ $\left.\left(\mathrm{O}_{2} / \mathrm{N}_{2}\right)_{\text {reference }}-1\right] \times 10^{6}$.

[13] Atmospheric flask samples taken in flasks at the high-altitude station Jungfraujoch (3580 m above sea level (asl), $46^{\circ} 33^{\prime} \mathrm{N}, 7^{\circ} 59^{\prime} \mathrm{E}$ ) at ambient pressure and stored in the laboratory in Bern (560 m asl) show a strong dependence of the measured $\mathrm{O}_{2} / \mathrm{N}_{2}$ ratio on the storage time. This correlation is attributed to permeation of gases through the Viton O-rings of the flasks' valves. In Figure $3, \delta \mathrm{O}_{2} / \mathrm{N}_{2}$ measurements from Jungfraujoch are plotted as a function of storage time. The $0.5 \mathrm{~L}$ flasks were stored at room temperature and at a mean ambient pressure of $950 \mathrm{hPa}$ over a period of up to 381 days. The mean sample pressure during the storage time was $\sim 720 \mathrm{hPa}$. Ordinary least squares regression yields a slope of $407 \pm 11$ per meg $\mathrm{yr}^{-1}$. Hence, even after a storage time of $\sim 100$ days, the effect of permeation clearly exceeded any real atmospheric signal. For example, the seasonal cycle amplitude at this site is expected to be of the order of 100 per meg [Keeling et al., 1993]. With permeation coefficients $K_{\mathrm{O}_{2}}=1.1 \times 10^{-15} \mathrm{~m}^{2} \mathrm{~s}^{-1} \mathrm{hPa}^{-1}$ and $K_{\mathrm{N}_{2}}=0.3 \times 10^{-15} \mathrm{~m}^{2} \mathrm{~s}^{-1} \mathrm{hPa}^{-1}$ for $\mathrm{O}_{2}$ and $\mathrm{N}_{2}$, respectively, one would expect a slope of 379 per meg $\mathrm{yr}^{-1}$, very close to the measured value.

[14] On the basis of these results, laboratory experiments were conducted to further test the stability of sample air composition in these flasks. Four $0.5 \mathrm{~L}$ flasks were filled to $655 \mathrm{hPa}$ with dry air from a high-pressure cylinder and were stored at ambient pressure $(950 \mathrm{hPa})$. The samples were analyzed 4 times during the storage period of 299 days, in which sample pressure decreased to $\sim 560 \mathrm{hPa}$. Figure 4 shows $\delta \mathrm{O}_{2} / \mathrm{N}_{2}$ deviations from the first measurement of each flask sample. These measurements agree well with predicted drift rates, indicating that the O-ring dimensions and permeation coefficients used to calculate predicted $\delta \mathrm{O}_{2} /$ $\mathrm{N}_{2}$ drift rates seem to be justified.

[15] Storage tests were also conducted by the Commonwealth Scientific and Industrial Research Organisation (CSIRO) in their $0.5 \mathrm{~L}$ glass flasks fitted with different O-ring materials (Viton, perfluoroalkoxy (PFA), and polytetrafluoroethylene (PTFE)) and at a range of sample pressures from 1000 to $2100 \mathrm{hPa}$. The results demonstrate the dependence of permeation rates on O-ring material and partial pressure differences [Langenfelds, 2002]. Each CSIRO flask is fitted with two valves (Glass Expansion, Melbourne, Australia), which differ from those manufac-

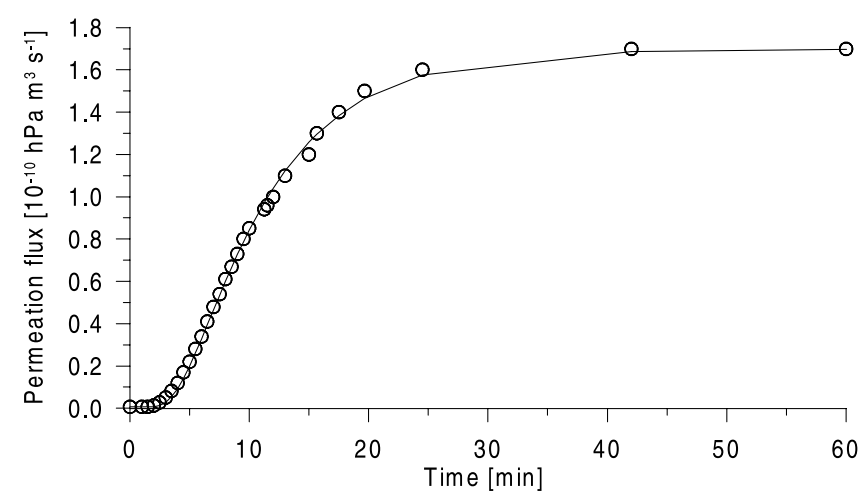

Figure 2. Helium permeation through a Viton O-ring. An initially evacuated flask was filled with helium to $950 \mathrm{hPa}$. The helium flux was then measured as a function of time (circles). The O-ring has a thickness of $\sim 1.7 \mathrm{~mm}$ and an exposed surface area of $\sim 20 \mathrm{~mm}^{2}$. A least squares fit of equation (7) to the measured data (line) yields permeation and solubility coefficients of $K_{\mathrm{He}}=15.1 \times 10^{-15} \mathrm{~m}^{2} \mathrm{~s}^{-1}$ $\mathrm{hPa}^{-1}$ and $S_{\mathrm{He}}=2.3 \times 10^{-5} \mathrm{hPa}^{-1}$, respectively. 
Table 1. Permeation Coefficients $K$ for Various Polymer Materials and Gases ${ }^{\mathrm{a}}$

\begin{tabular}{|c|c|c|c|c|c|c|c|c|}
\hline Material & $\mathrm{N}_{2}$ & $\mathrm{O}_{2}$ & $\mathrm{Ar}$ & $\mathrm{CO}_{2}$ & $\mathrm{H}_{2} \mathrm{O}$ & $\mathrm{He}$ & Temperature, ${ }^{\circ} \mathrm{C}$ & Source $^{b}$ \\
\hline \multirow[t]{5}{*}{ Viton } & $0.05-0.3$ & $1.0-1.1$ & & $5.8-6.0$ & 40 & $9-16$ & $20-30$ & 1 \\
\hline & & 1.1 & & & 216 & & 25 & 2 \\
\hline & 0.17 & 0.3 & & 3.5 & & 4.9 & 20 & 3 \\
\hline & 0.45 & & 1.65 & 2.4 & & 15.0 & 25 & 4 \\
\hline & 0.233 & 1.7 & & & & 12.8 & $23-30$ & 5 \\
\hline \multirow[t]{5}{*}{ PTFE $^{\mathrm{c}}$} & 0.14 & 0.04 & & 0.12 & 27 & & $20-30$ & 1 \\
\hline & 4.7 & & & & 23.3 & & 25 & 2 \\
\hline & 2.5 & 8.2 & & & & 570 & 23 & 6 \\
\hline & $1.44-2.4$ & $3.37-7.5$ & & 7.51 & & $30.1-523$ & 25 & 5 \\
\hline & 2.3 & 7.5 & 4.4 & & & 530 & 20 & 7 \\
\hline \multirow[t]{2}{*}{$\mathrm{NBR}^{\mathrm{d}}$} & $0.2-2.0$ & $0.7-6.0$ & & $5.7-48$ & 760 & $5.2-6$ & $20-30$ & 1 \\
\hline & $0.177-1.89$ & $0.72-6.15$ & & 5.63 & & $7.4-8$ & $20-25$ & 5 \\
\hline \multirow[t]{3}{*}{ Neoprene } & $0.8-1.2$ & $3-4$ & & $19-20$ & 1400 & $10-11$ & $20-30$ & 1 \\
\hline & $0.01-2$ & 3.0 & & $13.9-19.2$ & & $0.6-7.5$ & 25 & 5 \\
\hline & 0.19 & 1.4 & 1.2 & & & 7.2 & 20 & 7 \\
\hline \multirow[t]{2}{*}{ Polyurethane } & $0.4-1.1$ & $1.1-3.6$ & & $10-30$ & $260-9500$ & & $20-30$ & 1 \\
\hline & & 0.8 & & 10.5 & & 3.6 & $20-25$ & 5 \\
\hline \multirow[t]{3}{*}{ Silicone } & & $76-460$ & & $460-2300$ & 8000 & & $20-30$ & 1 \\
\hline & $75-210$ & $195-450$ & 450 & $1028-2280$ & & $238-263$ & room & 5 \\
\hline & 128 & 286 & & & & 156 & 20 & 3 \\
\hline \multirow[t]{2}{*}{ PCTFE $^{\mathrm{e}}$} & $0.004-0.3$ & $0.02-0.7$ & & $0.04-1$ & & & $20-30$ & 1 \\
\hline & & & & & 0.22 & & 25 & 6 \\
\hline
\end{tabular}

${ }^{\text {a }}$ The units are $10^{-15} \mathrm{~m}^{2} \mathrm{~s}^{-1} \mathrm{hPa}^{-1}$.

${ }^{\mathrm{b}}$ Sources are 1, Peacock [1980]; 2, Ma et al. [1995]; 3, Beckmann [1991]; 4, Laurenson and Dennis [1985]; 5, Parker Hannifin Corporation [2001]; 6, O'Hanlon [1989]; and 7, Holland et al. [1974].

${ }^{\mathrm{c}} \mathrm{PTFE}$ is polytetrafluoroethylene.

${ }^{\mathrm{d}} \mathrm{NBR}$ is acrylonitrile butadiene copolymer.

${ }^{\mathrm{e}} \mathrm{PCTFE}$ is polychlorotrifluoroethylene.

tured by Louwers Hapert in that the valve shafts are tapered and seals are formed by compression of the O-rings (Figure $1 b$ ). Figure 5 shows changes in $\delta \mathrm{O}_{2} / \mathrm{N}_{2}$ over storage times of up to 15 months in flask air samples filled to $1500 \mathrm{hPa}$. The higher sample pressure compared with a mean ambient pressure of $1000 \mathrm{hPa}$ led to $\delta \mathrm{O}_{2} / \mathrm{N}_{2}$ being depleted in these samples. All data points represent individual flask samples analyzed on a single occasion. Lowest drift rates of -61 per meg $\mathrm{yr}^{-1}$ were observed with Viton O-rings.

[16] To account for the geometric differences between Glass Expansion (GE) and Louwers Hapert (LH) valves, we measured helium permeation rates with a helium leak detector for both valve types fitted with Viton O-rings. This experiment showed that GE valves have a lower helium permeation rate than $\mathrm{LH}$ valves. Depending on the valve and on how tightly the GE valve is closed, the steady state permeation flux was a factor of 4-10 smaller for GE valves than for LH valves. This can be explained by the smaller area of the O-ring that is exposed to the gas in the closed GE valves. Because of the conical tip of the piston the O-ring is compressed into the groove cut in this tip, and the gap between the glass piston and the mating conical seat is smaller than for LH valves. Assuming a 7 times smaller area $\left(3 \mathrm{~mm}^{2}\right.$ instead of $\left.20 \mathrm{~mm}^{2}, d=1.7 \mathrm{~mm}\right)$, one would expect a $\delta \mathrm{O}_{2} / \mathrm{N}_{2}$ drift rate of -59 per meg $\mathrm{yr}^{-1}$, which is consistent with the observations.

[17] Figure 6 shows observed rates of drift as a function of sample pressure. Drift rates are near zero at sample pressures of $1000 \mathrm{hPa}$ and increase approximately linearly with sample pressure, providing compelling evidence that permeation is indeed the dominant modifying process.

\subsection{Permeation of Water Vapor}

[18] Variations of the amount of moisture in the sample air can induce different artifacts, like oxygen isotope exchange during flask storage between $\mathrm{CO}_{2}$ and water condensed on the flask walls [Gemery et al., 1996]. Depending on the analysis technique, water vapor can also adversely affect the measurement itself. In particular, for precise $\mathrm{O}_{2} / \mathrm{N}_{2}$ measurements it is a prerequisite that the analyzed sample air is dry. Therefore flask air samples are usually dried at the time of sampling either by a chemical drying agent (e.g., anhydrous magnesium perchlorate, $\left.\mathrm{Mg}\left(\mathrm{ClO}_{4}\right)_{2}\right)$ or by a cryogenic cold trap. However, because of the large permeability coefficients of most polymers for water vapor (Table 1), initially dry samples stored in the laboratory are intensely subject to water vapor permeation.

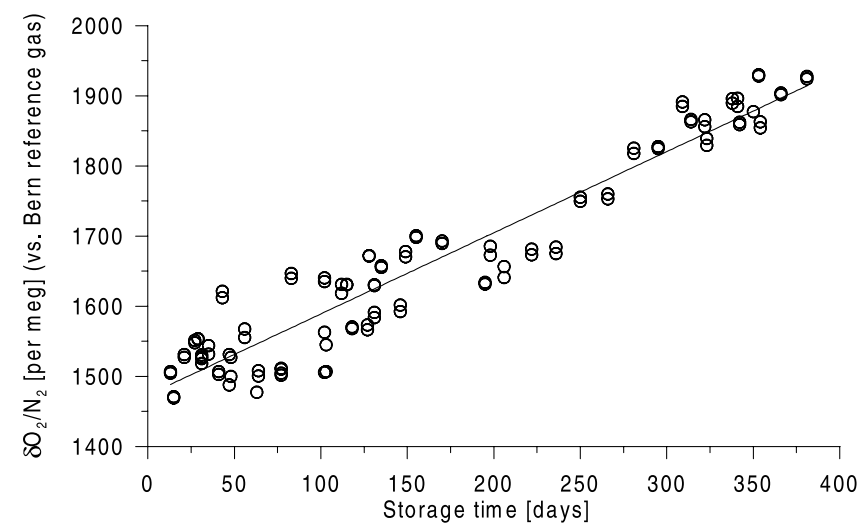

Figure 3. Measurements of $\delta \mathrm{O}_{2} / \mathrm{N}_{2}$ as a function of storage time. The samples are from Jungfraujoch and are stored in $0.5 \mathrm{~L}$ flasks, filled at ambient pressure at $3580 \mathrm{~m}$ above sea level and at a mean temperature of $-7^{\circ} \mathrm{C}$. Mean sample pressure at room temperature is $720 \mathrm{hPa}$, and mean ambient pressure is $950 \mathrm{hPa}$. Ordinary least squares regression yields a slope of $407 \pm 11$ per meg $\mathrm{yr}^{-1}$. 


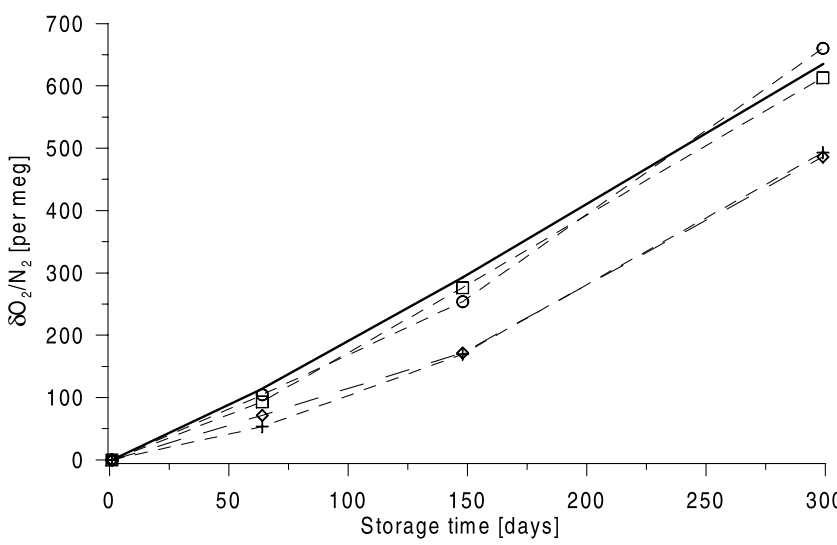

Figure 4. Changes in $\delta \mathrm{O}_{2} / \mathrm{N}_{2}$ due to storage in $0.5 \mathrm{~L}$ flasks. Measurements of the flasks UBE-107 (circles), UBE108 (squares), UBE-113 (diamonds), and UBE-114 (plus signs), filled to $655 \mathrm{hPa}$ and stored at $950 \mathrm{hPa}$, agree well with the calculated increase (solid line). Note that $\delta \mathrm{O}_{2} / \mathrm{N}_{2}$ does not increase linearly because of the pressure decrease of the sample air after each decanting.

Figure 7 shows the increasing amount of moisture as a function of storage time for air samples in 0.5 and $2.5 \mathrm{~L}$ flasks stored in the laboratory. Water vapor concentration was inferred by mass spectrometry from ion beam intensity at $\mathrm{m} / \mathrm{z} 18$, measured as a voltage $V_{18}$. After subtraction of the background signal, which is the $\mathrm{m} / \mathrm{z} 18$ intensity of a dry standard gas, $V_{18}$ was converted into a pressure using the $\mathrm{m} / \mathrm{z}$ intensity of $\mathrm{N}_{2}\left(V_{28}\right)$ and a correction factor, which accounts for the different ionization efficiencies of water vapor and $\mathrm{N}_{2}$.

[19] The 0.5 L flask air samples show an increase in moisture content of $3.87 \pm 0.17 \mathrm{hPa} \mathrm{yr}^{-1}$; the $2.5 \mathrm{~L}$ samples are enriched by $0.79 \pm 0.22 \mathrm{hPa} \mathrm{yr}^{-1}$. The $2.5 \mathrm{~L}$ flasks are a factor of $4.9 \pm 1.4$ less influenced by water vapor corresponding to the 5 times larger volume of these flasks. Both flask types had a sample pressure of $1000 \mathrm{hPa}$.

[20] Since for initially dry samples the water vapor pressure difference between sample and surrounding air is independent of sample pressure, the water vapor permeation

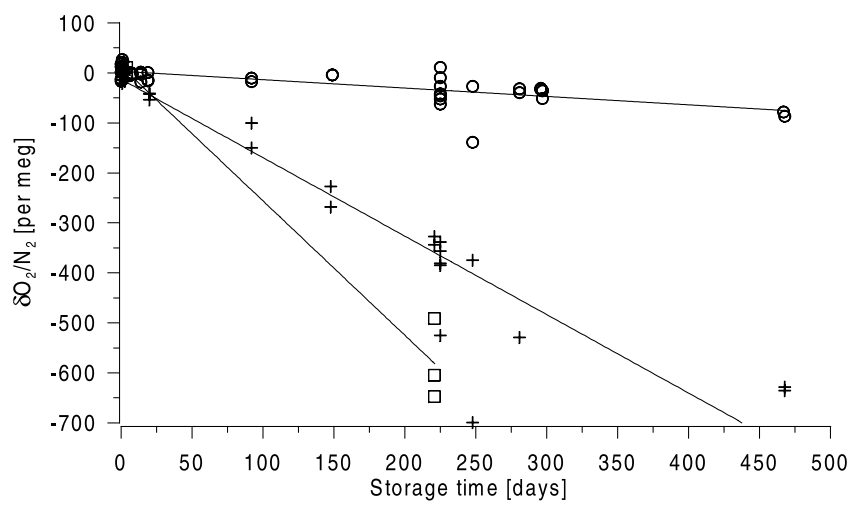

Figure 5. Changes in $\delta \mathrm{O}_{2} / \mathrm{N}_{2}$ due to storage in Commonwealth Scientific and Industrial Research Organisation's 0.5 L glass flasks fitted with Viton (circles, with linear regression represented by the line), perfluoroalkoxy (plus signs), and polytetrafluoroethylene (squares) O-rings.

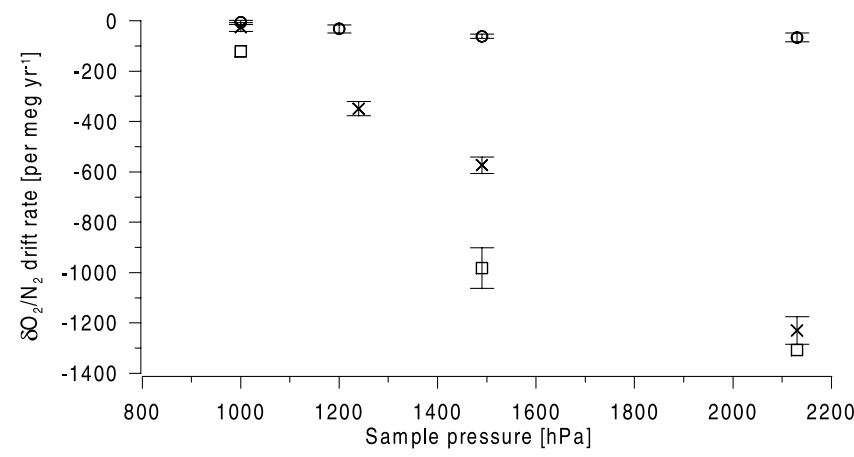

Figure 6. Rate of drift in $\delta \mathrm{O}_{2} / \mathrm{N}_{2}$ as a function of pressure and O-ring material (symbols same as for Figure 5), as determined by linear regression to data in Figure 5 (corresponding to the sample pressure of $1500 \mathrm{hPa}$ ) and data for other sample pressures (not shown). Error bars denote the standard error of the regression for data sets with more than two points.

flux is controlled by the humidity of the air at the flasks' storage location. With an average ambient vapor pressure of $14 \mathrm{hPa}$, which corresponds to $\sim 60 \%$ relative humidity at $20^{\circ} \mathrm{C}$, one obtains from the observed drift rates a permeation coefficient for water vapor through our Viton O-rings $\left(d=1.7 \mathrm{~mm}\right.$ and $\left.A=20 \mathrm{~mm}^{2}\right)$ of about $K_{\mathrm{H}_{2}} \mathrm{O}=$ $220 \times 10^{-15} \mathrm{~m}^{2} \mathrm{~s}^{-1} \mathrm{hPa}^{-1}$, which is consistent with the values listed in Table 1

[21] Thus permeation of water vapor may have adverse effects on trace gas measurements if sample air is not dried at the time of analysis. The increasing water vapor concentration leads to dilution of trace gas concentrations in sample air and might also lead to other storage- or analysis-related measurement artifacts for some species, including $\delta \mathrm{O}_{2} / \mathrm{N}_{2}$.

\subsection{Permeation of $\mathrm{Ar}$ and $\mathrm{CO}_{2}$}

[22] Changes in $\delta \mathrm{Ar} / \mathrm{N}_{2}$ and $\delta \mathrm{CO}_{2} / \mathrm{N}_{2}$ for the same samples as in Figure 4 are shown as a function of storage time in Figure 8 . The $\delta \mathrm{Ar} / \mathrm{N}_{2}$ values of these four samples show an increase of $399 \pm 32$ per meg after 299 days. Because of larger mass-dependent fractionation processes at the time of

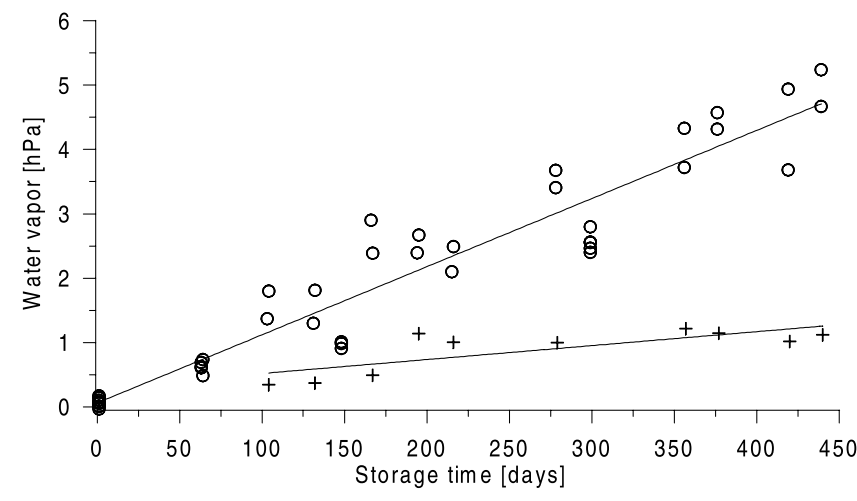

Figure 7. Water vapor as a function of storage time for 0.5 $\mathrm{L}$ (circles) and $2.5 \mathrm{~L}$ flasks (plus signs). The steeper slope for the $0.5 \mathrm{~L}$ flasks (factor of $4.9 \pm 1.4$ ) reflects the difference in flask volume. 

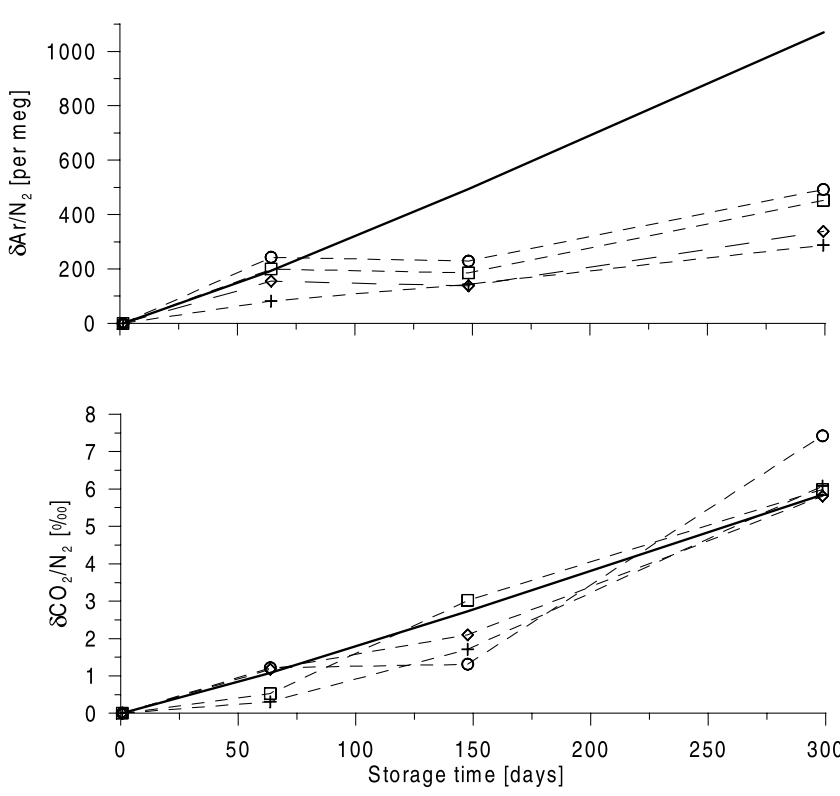

Figure 8. Changes in $\delta \mathrm{Ar} / \mathrm{N}_{2}$ and $\delta \mathrm{CO}_{2} / \mathrm{N}_{2}$ plotted as a function of the storage time and as a change relative to the first measurement for the same samples as in Figure 4: UBE-107 (circles), UBE-108 (squares), UBE-113 (diamonds), and UBE-114 (plus signs). (top) The $\delta \mathrm{Ar} / \mathrm{N}_{2}$ values show an increase of $399 \pm 32$ per meg after 299 days. On the basis of $K_{\mathrm{Ar}}=1.65 \times 10^{-15} \mathrm{~m}^{2} \mathrm{~s}^{-1} \mathrm{hPa}^{-1}$ one would expect an increase of 1071 per meg (line). (bottom) The $\mathrm{CO}_{2} / \mathrm{N}_{2}$ ratios (in \%o) are enriched by $5.8 \pm 0.3 \%$ after 299 days. The initial $\mathrm{CO}_{2}$ concentrations were between 401.6 and $406.9 \mathrm{ppm}$. The line is an estimate based on $K_{\mathrm{CO}_{2}}=6 \times 10^{-15} \mathrm{~m}^{2} \mathrm{~s}^{-1} \mathrm{hPa}^{-1}$ and an assumed mean $\mathrm{CO}_{2}$ concentration of $450 \mathrm{ppm}$ of laboratory air.

analysis and the poorer overall precision of $\delta \mathrm{Ar} / \mathrm{N}_{2}$ measurements, the storage drift is not as well resolved as for $\delta \mathrm{O}_{2} / \mathrm{N}_{2}$. The $\delta \operatorname{Ar} / \mathrm{N}_{2}$ drift rate is slightly smaller than that for $\delta \mathrm{O}_{2} / \mathrm{N}_{2}$. This is consistent with measurements from Langenfelds [2002]. However, an estimate based on a permeation coefficient of $K_{\mathrm{Ar}}=1.65 \times 10^{-15} \mathrm{~m}^{2} \mathrm{~s}^{-1} \mathrm{hPa}^{-1}$ (Table 1) gives an expected drift rate of 1070 per meg in 299 days for these samples. The predicted and observed drift rates differ by a factor of 2.7, suggesting that the value of $K_{\mathrm{Ar}}$ in Table 1 is too large.

[23] The initial $\mathrm{CO}_{2}$ concentrations of these samples were between 401.6 and $406.9 \mathrm{ppm}$. During the storage period of 299 days a $\delta \mathrm{CO}_{2} / \mathrm{N}_{2}$ change of $\sim 6 \%$ was observed (Figure 8 , bottom). This result can be explained with a $\mathrm{CO}_{2}$ permeation coefficient of $K_{\mathrm{CO}_{2}}=6 \times 10^{-15} \mathrm{~m}^{2} \mathrm{~s}^{-1} \mathrm{hPa}^{-1}$ (Table 1) and a mean $\mathrm{CO}_{2}$ concentration of ambient laboratory air of $450 \mathrm{ppm}$, i.e., $\sim 20 \%$ above a background atmospheric $\mathrm{CO}_{2}$ level of $370 \mathrm{ppm}$ (solid line, Figure 8).

[24] Unlike for $\mathrm{O}_{2}, \mathrm{~N}_{2}$, and $\mathrm{Ar}$, where concentration changes in ambient air are negligible with respect to permeation, the mole fraction of $\mathrm{CO}_{2}$ in laboratory air can change substantially. Changes in sample $\mathrm{CO}_{2}$ concentration are therefore highly dependent on the storage conditions. The $\mathrm{CO}_{2}$ partial pressure difference and the permeation flux are likely to vary with storage location and also with time. As the flask samples may be stored in a $\mathrm{CO}_{2}$-enriched environment or a well-ventilated room or as the presence of people in the laboratory may cause diurnal $\mathrm{CO}_{2}$ concentration variations, it is difficult to accurately predict $\mathrm{CO}_{2}$ permeation fluxes. Under some circumstances, there may be little or no change in the $\mathrm{CO}_{2}$ concentration of sample air, for example, where a background air sample at a pressure of $1200 \mathrm{hPa}$ is stored in an environment with $\mathrm{CO}_{2}$ enriched by $20 \%$ above background level.

[25] In terms of a mixing ratio the permeation of other gases may also become important. The increasing amount of $\mathrm{CO}_{2}$ in the samples of Figure 8 is diluted by the simultaneous influx of water vapor. If the sample air is not dried again at the time of analysis and assuming an ambient water vapor pressure of $14 \mathrm{hPa}$ and $K_{\mathrm{H}_{2}} \mathrm{O}=220 \times$ $10^{-15} \mathrm{~m}^{2} \mathrm{~s}^{-1} \mathrm{hPa}^{-1}$, one would obtain a $\mathrm{CO}_{2}$ concentration drift after 299 days of $-0.2 \mathrm{ppm}$ for the conditions as outlined in Figure 8. If the sample air is dried prior to measurement, the $\delta \mathrm{CO}_{2} / \mathrm{N}_{2}$ increase of $6 \%$ corresponds to a $\mathrm{CO}_{2}$ concentration change of $+2.4 \mathrm{ppm}$. Thus $\mathrm{CO}_{2}$ measurements from flask samples are not only dependent on flask volume and sample pressure but are also highly sensitive to ambient $\mathrm{CO}_{2}$ mixing ratios and analysis techniques. Changes in $\mathrm{CO}_{2}$ of the magnitude reported here are potentially much larger than targets for $\mathrm{CO}_{2}$ intercomparability among laboratories of $\pm 0.1 \mathrm{ppm}$ in the Northern Hemisphere or $\pm 0.05 \mathrm{ppm}$ in the Southern Hemisphere recommended by the World Meteorological Organization [2003].

[26] Effects of permeation will also influence the isotopic composition of $\mathrm{CO}_{2}$ in flask samples. It is likely that isotopic fractionation is associated with the permeation process itself; that is, the lighter isotopomeres are favored over the heavier ones, comparable, for example, with diffusion of $\mathrm{CO}_{2}$ through air. Moreover, the influx of water vapor might lead to ${ }^{18} \mathrm{O}$ isotopic exchange between water and $\mathrm{CO}_{2}$.

[27] Permeation can affect the isotopic composition, even in the absence of permeation fractionation effects. Changes in $\delta^{13} \mathrm{C}$ occur if flasks are stored in an environment enriched by biogenic $\mathrm{CO}_{2}$, such as in a laboratory. Assuming an average enrichment of $80 \mathrm{ppm}$ with $\delta^{13} \mathrm{C}=-25 \%$ (versus Vienna Peedee belemnite) compared with $-8 \%$ o for background air, the drift rate for $0.5 \mathrm{~L}$ flasks with $600 \mathrm{hPa}$ sample pressure would be about $-0.05 \% \mathrm{yr}^{-1}$. Thus changes in isotopic composition become potentially significant if samples are stored for long periods in a $\mathrm{CO}_{2}$-rich environment.

[28] In many laboratories it is the practice to store pure $\mathrm{CO}_{2}$ samples for a limited period of time in test tubes sealed by an O-ring valve. On some occasions, for example, when shipping such tubes to other laboratories, storage times can be up to several weeks, and permeation effects for these samples with their large $\mathrm{CO}_{2}$ gradient can become large. These effects were already observed in the 1980s [Keeling et al., 1989] but were not studied in detail at that time. New investigations, now with the aid of the permeation model presented here, are under way at the Centrum voor IsotopenOnderzoek (CIO), Groningen, Netherlands. They will produce, among other things, $\delta^{13} \mathrm{C}$ and $\delta^{18} \mathrm{O}$ permeation fractionation factors.

\section{Double O-Ring Valves}

[29] Tests with different O-ring materials and the data in Table 1 show that Viton has comparably low permeation coefficients. So far, it is the preferred material for O-rings in 
glass flasks used for $\mathrm{O}_{2} / \mathrm{N}_{2}$ measurement programs. A new approach to further reduce permeation influences is a new valve design, the so-called double O-ring valves. This design was, to our knowledge, first discussed and used by the National Institute for Environmental Studies, Tsukuba, Japan. In contrast to conventional valves, where a single O-ring seals the sample air from the atmosphere, the double O-ring valves incorporate a second O-ring, which creates an additional small buffer volume (Figure 1c). Initially, this buffer volume also contains sample air, eliminating any net permeation fluxes between flask and buffer volume. In first order, permeation due to partial pressure gradients between the sample and ambient air only leads to changes of air composition in the buffer volume. Only these changes in the buffer volume are eventually passed on to the flask volume through permeation. The larger the buffer volume is and the smaller the ambient/buffer permeation fluxes are, the more effective the double O-ring valve is in reducing modification of sample air composition. The construction of the double O-ring valve allows a sequential opening in order to be able to evacuate the buffer volume prior to decanting sample air into analytical inlet systems.

[30] The permeation influence with double O-ring valves can be calculated by solving two coupled linear differential equations for the partial pressures in the buffer and flask volume, respectively. In addition to calculations, different flask storage tests with double O-ring valves were carried out. Figure 9 shows a storage drift test performed at the Max Planck Institute for Biogeochemistry (MPI-BGC), Jena, Germany. Here 1.4 L flasks equipped with two custommade double O-ring valves (Louwers Hapert, Netherlands) and filled with dry sample air to $2000 \mathrm{hPa}$ were stored at ambient pressure and were measured several times during $\sim 200$ days. The buffer volume of each valve is $0.6 \mathrm{~mL}$. Six flasks show a change in $\delta \mathrm{O}_{2} / \mathrm{N}_{2}$ of -3 to -31 per meg after 200 days storage in accordance with the calculated drift rate (solid line in Figure 9). Three samples, however, are depleted in $\delta \mathrm{O}_{2} / \mathrm{N}_{2}$ by -70 to -92 per meg, which is close to the expected change for single O-ring flasks of -116 per meg. Possible explanations for this different behavior are different initial flask conditions, i.e., impurities in the flasks, or oxidation of grease used to lubricate the Viton O-rings.

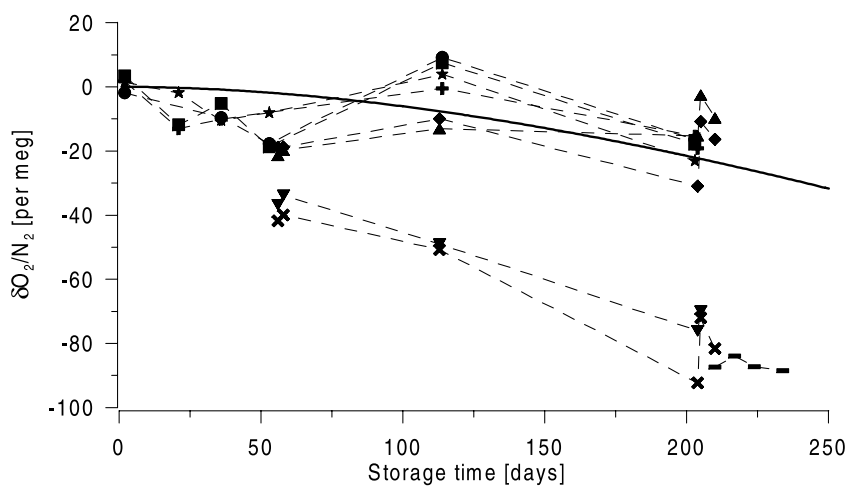

Figure 9. Changes in $\delta \mathrm{O}_{2} / \mathrm{N}_{2}$ due to storage for nine $1.4 \mathrm{~L}$ flasks equipped with two double O-ring valves (symbols, dashed lines). The buffer volume of each valve is $0.6 \mathrm{~mL}$, and the sample air pressure is $2000 \mathrm{hPa}$. The solid line represents the expected drift rate.

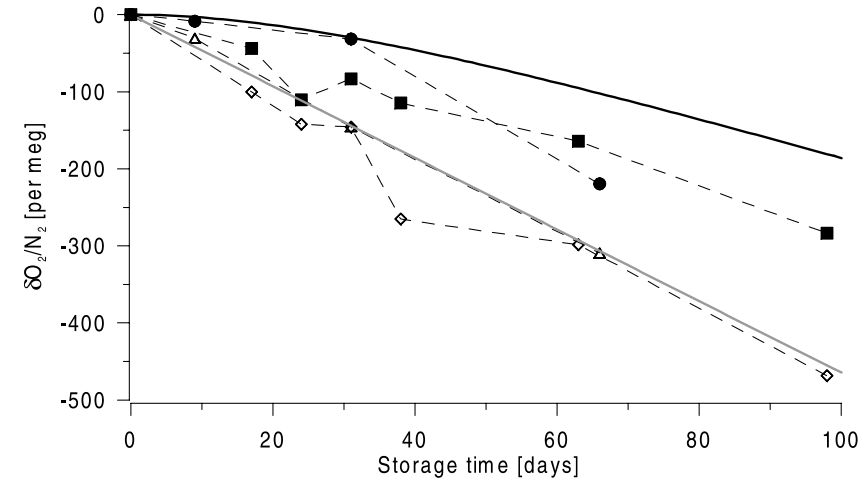

Figure 10. Comparison of $\delta \mathrm{O}_{2} / \mathrm{N}_{2}$ drifts for $0.35 \mathrm{~L}$ flasks equipped with either two single O-ring (open symbols) or two double O-ring (solid symbols) valves. The buffer volume of the double O-ring valves is $0.08 \mathrm{~mL}$. Sample air pressure is $1000 \mathrm{hPa}$, and ambient storage pressure was kept below $4 \mathrm{hPa}$ for both flask types. The calculated changes for single and double O-ring flasks are represented by the shaded and the solid line, respectively.

[31] A different experimental setup was used at the CIO, Groningen, for a comparison test between single and double O-ring valves. All flasks had a volume of only $0.35 \mathrm{~L}$ and were filled with dry air to ambient pressure $(1000 \mathrm{hPa})$. During the storage time they were connected to a vacuum line, which kept the pressure below $4 \mathrm{hPa}$ in order to sustain a pressure gradient of $1000 \mathrm{hPa}$ across the O-rings. The flasks were fitted with two valves each (Louwers Hapert, Netherlands), either with single or double O-rings. The double O-ring stopcocks were produced at the workshop in Groningen. The buffer volume of these valves is about $0.08 \mathrm{~mL}$.

[32] The experiment was carried out twice, once with 16 flasks stored over a period of 98 days and once with 8 flasks stored over 66 days. Samples were measured after a range of storage times and in pairs at a time, in each case including a single and a double O-ring flask. Each sample was analyzed only once so that sample pressures were constant over the duration of the storage test.

[33] The results are plotted in Figure 10 as the deviation from the mean of the measurements on the filling day. Solid symbols represent individual samples from double O-ring flasks, and open symbols represent samples from single O-ring flasks. The single O-ring flasks show a change in $\delta \mathrm{O}_{2} / \mathrm{N}_{2}$ of about -470 per meg after 98 days, which is in good agreement with the predicted change for this test setup (shaded line). The drift rate for the double O-ring flasks is clearly lower. However, the calculated drift rate leads to a depletion of 181 per meg (solid line), whereas the measurements reveal a depletion of $\sim 280$ per meg over 98 days storage, which corresponds to an improvement factor of only about 1.7 compared with the single O-ring flasks. Independent of the O-ring dimensions, the permeation coefficients, and the size of the buffer volume, one would expect the double O-ring flasks to perform at least a factor of 2 better with respect to permeation than the single O-ring flasks because the overall thickness of polymer for any gas to permeate is doubled with two O-rings. The reason why this is not the case for the presented experiment is not yet 


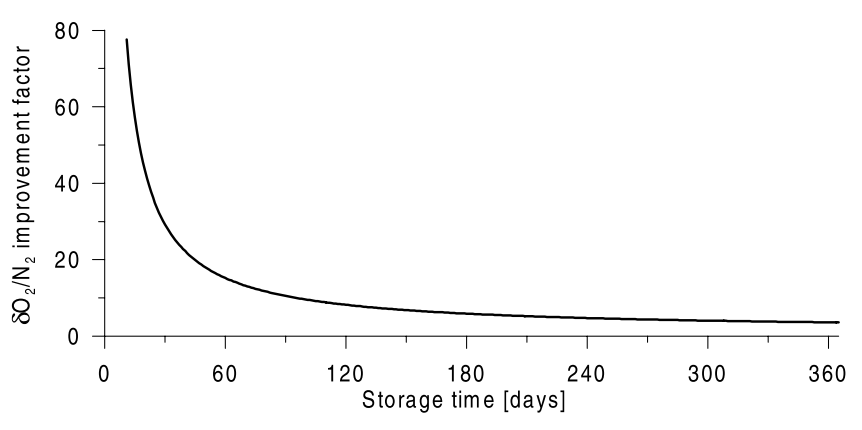

Figure 11. Calculated ratio of single $\mathrm{O}$-ring to double $\mathrm{O}$-ring flask storage drifts (improvement factor) for $\delta \mathrm{O}_{2} / \mathrm{N}_{2}$ and double O-ring flasks with a buffer volume of $0.6 \mathrm{~mL}$ per valve as a function of time. This improvement factor is nearly independent of flask volume and pressure gradients.

known. Part of the explanation might be the different absolute pressure gradients across the two O-rings, which causes different plastic deformations of the two O-rings.

[34] On the basis of theoretical considerations it is clear that the performance of double O-ring flasks compared with single O-ring flasks becomes less efficient the longer the storage period is. Double O-ring flasks with a buffer volume of $0.6 \mathrm{~mL}$ per valve and O-ring dimensions of $d=1.7 \mathrm{~mm}$ and $A=20 \mathrm{~mm}^{2}$ lead to a substantial improvement in $\delta \mathrm{O}_{2} /$ $\mathrm{N}_{2}$ stability only for the first few weeks of storage. The permeation influence compared with single O-ring flasks is reduced after 1 month by a factor of 29 and after 1 year by a factor of only 3.5 (Figure 11). The improvement factor is, to a good approximation, independent of flask volume and pressure gradients.

[35] Remarkably, a steady state is almost reached for $\mathrm{CO}_{2}$ and water vapor after only 1 week because of the large $\mathrm{CO}_{2}$ and water vapor permeabilities. The buffer volume is rapidly equilibrated with these gases, reducing the permeation influence of sample air only by about a factor of 2 compared with single O-ring valves. Even a 10 times larger buffer volume would result only in a moderate reduction of water vapor content of $6 \%$ after a storage time of 1 year.

\section{Conclusions and Outlook}

[36] Permeation of atmospheric gases through O-rings used to seal glass flask valves can substantially influence sample air composition. Large storage drifts, which can impair atmospheric $\delta \mathrm{O}_{2} / \mathrm{N}_{2}$ studies, have been found for samples with significant partial pressure differences after a storage period of up to 1 year. Likewise, changes of $\delta \mathrm{Ar} / \mathrm{N}_{2}$, water vapor, and $\mathrm{CO}_{2}$ concentration occurred because of permeation fluxes of these gases. Appropriate sampling and storage strategies have to be chosen to ensure reliable flask measurements. Obviously, short storage times improve the sample quality. Larger flask volumes can also help to attenuate storage effects. However, for logistical reasons the flask volumes are kept small $(0.5-2.5 \mathrm{~L})$. For $\mathrm{O}_{2} / \mathrm{N}_{2}$ studies the flasks must be filled preferentially to a pressure similar to the ambient storage pressure in order to minimize permeation effects.

[37] Flasks intended for $\mathrm{CO}_{2}$ measurements should be stored in an environment of known $\mathrm{CO}_{2}$ concentration so that permeation effects can be well characterized and corrected for. In practice, the most convenient way of storing flasks in a $\mathrm{CO}_{2}$-controlled environment is to store them in a well-ventilated area where $\mathrm{CO}_{2}$ levels are always close to background.

[38] The water vapor content increases for initially dried samples if they are stored at ambient humidity. If water vapor affects the analysis, the sample air therefore has to be dried again prior to the measurement after long storage periods.

[39] The surface area and the thickness of the sealing material vary with different valve types. Such geometric differences can also result in significant differences in permeation rates. Where samples must contain overpressure, e.g., for reasons concerning introduction of air samples to analytical instruments, the double O-ring valves can considerably reduce permeation influences, at least for storage times of up to a few weeks. Other methods for reducing permeation effects are under investigation. One approach involves using seals constructed from Kel-F (polychlorotrifluoroethylene (PCTFE)). Compared with Viton, Kel-F has the advantage of lower permeation coefficients but the disadvantage of its greater hardness, making it more difficult to achieve reliable glass-polymer seals. Tests with Kel-F-sealed glass flasks are currently being performed at the MPI-BGC, Jena, Germany.

[40] Acknowledgments. This work was supported by the Swiss National Science Foundation and the EC Projects MILECLIM, ALPCLIM, and AEROCARB, an EC Project of the CARBOEUROPE cluster. We thank P. Nyfeler for technical assistance and R. Francey and P. Steele for helpful discussions. Valuable comments were provided by R. Keeling and an anonymous reviewer. We acknowledge the International Foundation High Altitude Research Stations Jungfraujoch and Gornergrat (HFSJG), which made it possible to take flask samples at Jungfraujoch.

\section{References}

Barrer, R. M. (1941), Diffusion in and Through Solids, Cambridge Univ. Press, New York.

Beckmann, W. (1991), Gasdurchlässigkeit von Elastomeren, Kautsch. Gummi Kunstst., 44(4), 323-329.

Bender, M., T. Ellis, P. Tans, R. Francey, and D. Lowe (1996), Variability in the $\mathrm{O}_{2} / \mathrm{N}_{2}$ ratio of Southern Hemisphere air, 1991-1994: Implications for the carbon cycle, Global Biogeochem. Cycles, 10(1), 9-21.

Gemery, P. A., M. Trolier, and J. W. C. White (1996), Oxygen isotope exchange between carbon dioxide and water following atmospheric sampling using glass flasks, J. Geophys. Res., 101(D9), 14,415-14,420.

Holland, L., W. Steckelmacher, and J. Yarwood (1974), Vacuum Manual, E. and F. N. Spon, London.

Keeling, C. D., R. B. Bacastow, A. F. Carter, S. C. Piper, T. P. Whorf, M. Heimann, W. G. Mook, and H. Roeloffzen (1989), A three-dimensional model of atmospheric $\mathrm{CO}_{2}$ transport based on observed winds: 1. Analysis of observational data, in Aspects of Climate Variability in the Pacific and Western Americas, Geophys. Monogr. Ser., vol. 55, edited by D. H. Peterson, pp. 165-236, AGU, Washington D. C.

Keeling, R., R. Najjar, M. Bender, and P. Tans (1993), What atmospheric oxygen measurements can tell us about the global carbon cycle, Global Biogeochem. Cycles, 7(1), 37-67.

Keeling, R., A. Manning, E. McEvoy, and S. Shertz (1998), Methods for measuring changes in atmospheric $\mathrm{O}_{2}$ concentration and their application in Southern Hemisphere air, J. Geophys. Res., 103(D3), 3381-3397.

Langenfelds, R. L. (2002), Studies of the global carbon cycle using atmospheric oxygen and associated tracers, Ph.D. thesis, Univ. of Tasmania, Hobart, Tasmania, Australia.

Laurenson, L., and N. T. M. Dennis (1985), Permeability of common elastomers for gases over a range of temperatures, J. Vac. Sci. Technol. A, 3(3), 1707-1710.

Ma, C., E. Shero, V. Nishith, S. L. Gilbert, and F. Shadman (1995), Permeation of moisture and oxygen through polymeric O-rings, J. IES, 38(2), $43-46$.

O'Hanlon, J. F. (1989), A User's Guide to Vacuum Technology, 2nd ed., John Wiley, Hoboken, N. J.

Parker Hannifin Corporation (2001), Parker O-ring handbook, Rep. ORD 5700, Lexington, Ky.

Peacock, R. N. (1980), Practical selection of elastomer materials for vacuum seals, J. Vac. Sci. Technol., 17(1), 330-336. 
Perkins, W. G. (1973), Permeation and outgassing of vacuum materials, J. Vac. Sci. Technol., 10(4), 543-556.

World Meteorological Organization (2003), Report of the 11th WMO/ IAEA Meeting of Experts on Carbon Dioxide Concentration and Related Tracer Measurement Techniques, Tokyo, Japan, 25-28 Sep. 2001, WMO/GAW Rep. 148, World Meteorol. Organ. Global Atmos. Watch, Geneva, Switzerland.

W. A. Brand, Max Planck Institute for Biogeochemistry, Hans-KnoellStrasse 10, D-07745 Jena, Germany. (wbrand@bgc-jena.mpg.de)
R. Langenfelds, CSIRO Atmospheric Research, Private Bag 1, Aspendale, Victoria 3195, Australia. (ray.langenfelds@csiro.au)

M. Leuenberger and P. Sturm, Climate and Environmental Physics, Physics Institute, University of Bern, Sidlerstrasse 5, CH-3012 Bern, Switzerland. (leuenberger@climate.unibe.ch; sturm@climate.unibe.ch)

H. A. J. Meijer, R. E. M. Neubert, and C. Sirignano, Centrum voor IsotopenOnderzoek, Rijksuniversiteit Groningen, Nijenborgh 4, 9747 AG NL-Groningen, Netherlands. (meijer@phys.rug.nl; neubert@phys.rug.nl; sirignano@phys.rug.nl)

Y. Tohjima, Atmospheric Environment Division, National Institute for Environmental Studies, 16-2 Onogawa, Tsukuba 305-8506, Ibaraki, Japan. (tohjima@nies.go.jp) 